\title{
Isolation and Identification of an Antimutagenic Phthalate Derivative Compound from Octopus (Paraoctopus limaculatus)
}

\author{
Susana-Gabriela Cruz-Ramírez ${ }^{1}$, Carmen-María López-Saiz ${ }^{1}$, Maribel \\ Plascencia-Jatomea ${ }^{1}$, Lorena Machi-Lara ${ }^{2}$, Fernando Rocha-Alonzo ${ }^{3}$, Enrique \\ Márquez-Ríos ${ }^{1}$ and Armando Burgos-Hernández ${ }^{1 *}$ \\ ${ }^{1}$ Departamento de Investigación y Posgrado en Alimentos, ${ }^{2}$ Departamento de Investigación en Polímeros y Materiales, \\ ${ }^{3}$ Departamento de Ciencias Químico-Biológicas, Universidad de Sonora, Apartado Postal 1658, Hermosillo, Sonora, México \\ *For correspondence: Email: aburgos@guayacan.uson.mx; Tel: +526-622-592-208; Fax: +526-622-592-209
}

\begin{abstract}
Purpose: To isolate and evaluate the antimutagenic properties of compounds previously identified in octopus (Paraoctopus limaculatus).

Methods: Octopus fractions, previously obtained by a sequential thin layer chromatography (TLC) procedure, were subjected to further fractionation by TLC and their anti-mutagenic activity monitored using Salmonella tester strains TA98 and TA100 with metabolic activation (S9) in Ames test. The isolated fractions were subjected to structural studies by Fourier transformed infrared spectroscopy (FT$I R)$, nuclear magnetic resonance $\left({ }^{1} \mathrm{H}\right.$ and $\left.{ }^{13} \mathrm{C} N M R\right)$, and gas chromatography-mass spectrometry. Results: Five new fractions were obtained from a previously isolated and reported anti-mutagenic octopus fraction. Fractions RB21321b2 and RB21321b3 inhibited $>80 \%$ of the mutagenicity induced by $500 \mathrm{ng}$ AFB1 on both tester strains and were selected for chemical/structural characterization. Data from IR and ${ }^{1} \mathrm{H}$ and ${ }^{13} \mathrm{C}$ NMR suggested the presence of phthalate type of compounds. GC-MS analysis revealed $278 \mathrm{~m} / \mathrm{z}$ for both fractions which is consistent with a butyl isobutyl phthalate structure.

Conclusion: Based on the findings, the compound responsible for the high anti-mutagenic activity of the isolated fraction from octopus is 1-butyl-2-isobutyl-phthalate.
\end{abstract}

Keywords: Octopus, Anti-mutagenic, Paraoctopus limaculatus, 1-Butyl-2-isobutyl-phthalate

Tropical Journal of Pharmaceutical Research is indexed by Science Citation Index (SciSearch), Scopus, International Pharmaceutical Abstract, Chemical Abstracts, Embase, Index Copernicus, EBSCO, African Index Medicus, JournalSeek, Journal Citation Reports/Science Edition, Directory of Open Access Journals (DOAJ), African Journal Online, Bioline International, Open-J-Gate and Pharmacy Abstracts

\section{INTRODUCTION}

Covering $>70 \%$ of the planet's surface, marine ecosystems comprise a continuous resource of immeasurable biological activities and immense chemical entities. Marine fauna and flora usually produce secondary metabolites with structural features distinct from other natural sources, which are of interest for potential industrial and medical applications [1,2]. One of the components of interest is the lipid fraction of marine organisms that have been associated with the prevention of chronic degenerative diseases such as cardiovascular diseases and cancer [3-7]. Unsaturated fatty acids $\omega-3$ and $\omega$ 6 isolated from different marine sources have been shown to be anti-mutagenic and anticarcinogenic [8].

Recent studies have identified compounds with biological activity such as rhizochalin, an antimicrobial and cytotoxic marine two-headed 
sphingolipid isolated from the sponge (Rhizochalina incrustata) [9]; alkylglycerols, from shark (Centrophorus squamosus) liver oil with anti-tumor and anti-metastasis activities [10]; sulfoglycolipid, from marine macroalgae (Porphyra crispata) which inhibited the growth of human hepatocellular carcinoma cell line HepG2 [11]; and terpenoids, isolated from marine organisms and sponges which were found to exhibit anti-inflammatory, antimicrobial, and antitumor activities [12]. In a previous research work [13], anti-mutagenic fractions were obtained from octopus and the chemical attributes of the bioactive compounds contained in these fractions were partially characterized. The aim of this research work was to identify the bioactive agents that were previously detected in octopus (Paraoctopus limaculatus) and were reported by Moreno-Félix et al [13].

\section{EXPERIMENTAL}

\section{Testing species}

Octopus (Paraoctopus limaculatus) was obtained from a local market in Hermosillo, Sonora, México, and transported in ice to the University of Sonora. Octopus tentacles were separated, packed, and stored at $-20^{\circ} \mathrm{C}$ until analysis.

The extraction of the lipid fraction, carried out avoiding direct exposition to light, was performed according to the methodology reported by Burgos-Hernández et al [14] and Moreno-Felix et al [13]. A sample of $100 \mathrm{~g}$ of octopus muscle and five parts $(\mathrm{w} / \mathrm{v})$ of $\mathrm{CHCl}_{3}$ were homogenized in a blender at high speed for $1 \mathrm{~min}$. The resulting homogenate was poured into a flask and agitated for 40 min in a Wrist Action Burrel Shaker (Burrel Corporation, Pittsburg, PA, U.S.). The mixture was filtered through a Whatman No. 1 filter paper under vacuum and the filtrate was evaporated to dryness. The extract was then re-dissolved in a chloroform-acetone solution (9:1 v/v).

\section{Fractionation of octopus extract}

The fractionation of octopus extract was performed according to the method of BurgosHernandez et al [14]. A $2.0 \mathrm{~mL}$ aliquot of octopus muscle extract was applied on to a $3.0 \mathrm{~mm}$ thick silica gel-coated preparative TLC plate and developed with chloroform-acetone solution (9:1 $\mathrm{v} / \mathrm{v})$. Fluorescent bands, identified by their $\mathrm{Rf}$ values, were scrapped off the plate and the contents of the silica were extracted with $2 \times 25$ $\mathrm{mL}$ chloroform-methanol-acetone solution (9:1:1 $\mathrm{v} / \mathrm{v} / \mathrm{v})$. The extracts were re-suspended, serially diluted in dimethyl sulfoxide (DMSO) and tested for anti-mutagenicity. When anti-mutagenic bands were detected, their contents were again obtained from a fresh muscle sample following the same procedure and were subjected to further fractionation (Figure 1).

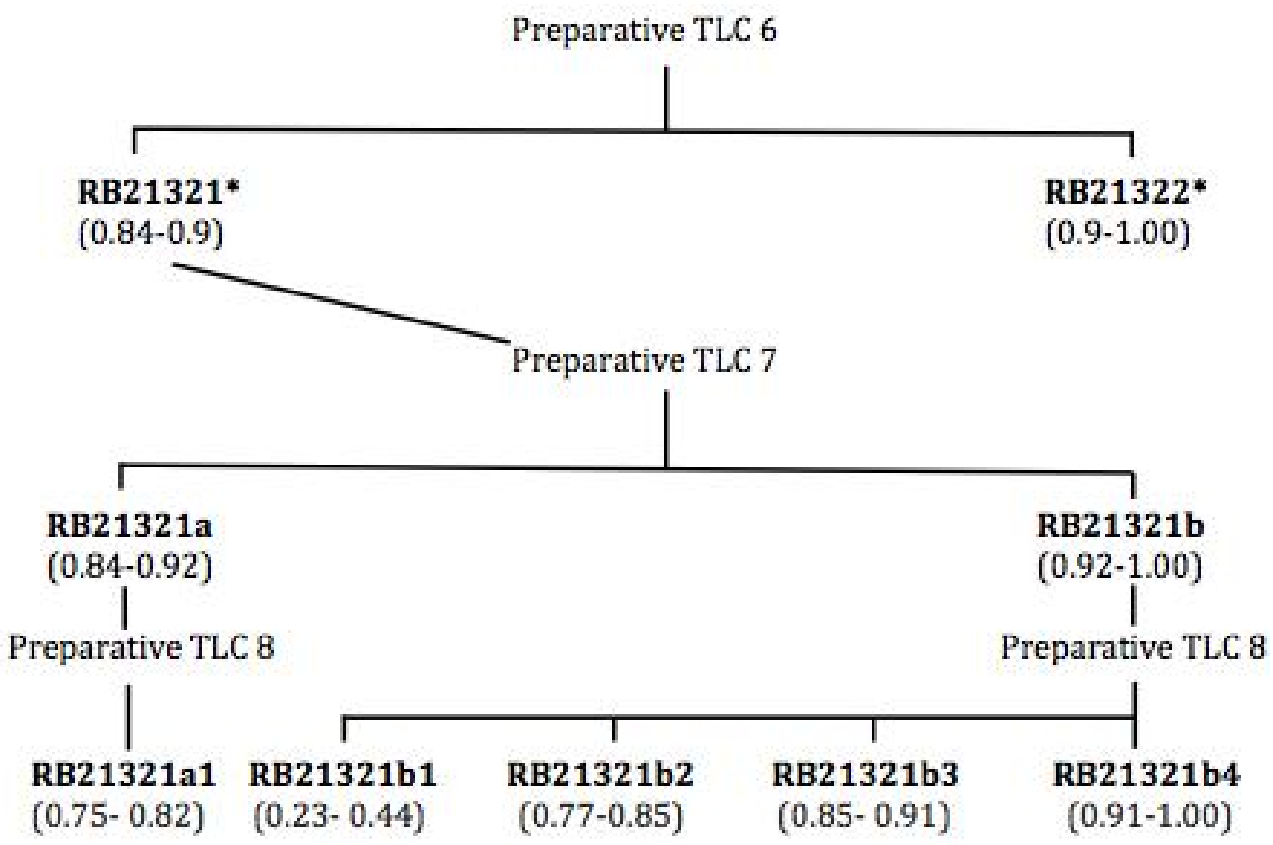

Figure 1: Schematic for separation and isolation of anti-mutagenic fractions from octopus. Numbers in parenthesis are Rf values. * Obtained and previously reported by Moreno-Félix et al [13] 


\section{Bacterial cultures}

Salmonella typhimurium TA98 and TA100 tester strains were used. Fresh overnight tester axenic cultures were stored at $-80{ }^{\circ} \mathrm{C}$ and routinely checked to confirm genetic characteristics using the procedure described by Maron and Ames [15].

\section{Antimutagenicity test}

The Ames test was used to test the antimutagenic activity of the dry extracts obtained from preparative-thin layer chromatography (TLC) fractionation procedures. Extracts were reconstituted with dimethyl sulfoxide (DMSO) to a final concentration of $10 \mathrm{mg} / \mathrm{mL}$, serially diluted $(1: 10 \mathrm{v} / \mathrm{v})$ also with DMSO and spiked with pure aflatoxin AFB1 (AFB1) (Sigma-Aldrich, St. Louis, $\mathrm{MO}$, U.S.) to a final concentration of $500 \mathrm{ng}$ of AFB1/100 $\mu \mathrm{L}$ of diluted extract. Metabolic activation system S9 mix (Aroclor 1254-induced, Sprague-Dawley male rat liver in $0.154 \mathrm{M} \mathrm{KCl}$ solution, Molecular Toxicology, Inc.; Annapolis, MD, U.S.) was used to bioactivate AFB1. Residual mutagenicity of AFB1 was assayed using the standard plate incorporation procedure described by Maron and Ames (1983). Different AFB1 concentrations, including 500 ng AFB1/100 $\mu \mathrm{L}$, were used as controls for both tester strains. All assays were performed in triplicate.

\section{Structural studies}

Chemical characterization of the compounds isolated from octopus bioactive fractions was performed through Fourier Transformed Infrared (FT-IR), nuclear magnetic resonance $\left({ }^{1} \mathrm{H}\right.$ and ${ }^{13} \mathrm{C}$ NMR), and mass spectrometry analyses. Compounds were dissolved in HPLC-grade acetone before the analysis. The FT-IR spectrum was obtained using the GX Perkin Elmer equipment. The percentage transmittance was measured against the wave number from 4000 to $400 \mathrm{~cm}^{-1}$. NMR spectroscopy was performed for the compound dissolved in deuterated chloroform $\left(\mathrm{CDCl}_{3}\right)$, and the spectra were recorded on a Bruker Avance $400 \mathrm{MHz}$ using tetramethylsilane (TMS) as a reference. The mass spectrum was obtained with a VARIAN 431-GC gas chromatograph equipped with a VARIAN 210-MS ion trap mass detector. Chromatographic separation was achieved using a capillary column Factor Four TM VF-5ms (30 m x $0.25 \mathrm{~mm} \times 0.25 \mu \mathrm{m}$ ) purchased from VARIAN and ultra-high purity helium was used as carrier gas at a constant flow of $13 \mathrm{~mL} / \mathrm{min}$, in splitless injection mode. Samples were dissolved in HPLC-grade chloroform and a $3.0 \mu \mathrm{L}$ aliquot was injected. An initial oven temperature of $120{ }^{\circ} \mathrm{C}$ was held for $5 \mathrm{~min}$, followed by a ramp of 10 ${ }^{\circ} \mathrm{C} / \mathrm{min}$ to $180{ }^{\circ} \mathrm{C}$, holding for $30 \mathrm{~min}$, followed by a ramp of $10{ }^{\circ} \mathrm{C} / \mathrm{min}$ to $210{ }^{\circ} \mathrm{C}$, holding for 20 min. The injection port temperature was maintained at $250{ }^{\circ} \mathrm{C}$. Total chromatographic separation was achieved in $64 \mathrm{~min}$. The transfer line, manifold, and trap temperatures were 205, 80 and $150{ }^{\circ} \mathrm{C}$, respectively. All mass spectra were acquired in the electron impact mode. Ionization was not applied during the first 2 min, to avoid solvent overloading. The scan was performed from 40 to $500 \mathrm{~m} / \mathrm{z}$ with a scan rate of $1 \mathrm{scan} / \mathrm{s}$.

\section{Statistical analysis}

Data were analyzed using analysis of variance (ANOVA) with Tukey-Kramer test $(p<0.05)$ with the aid of JMP statistical software (Visual statistical discovery, version software 5.01).

\section{RESULTS}

\section{Anti-mutagenic activity}

Contents from band RB21321 resulted from the sixth TLC fractionation step of octopus muscle were used for further fractionation in the present study, due to the higher inhibition exerted on the mutagenicity of AFB1 and shown in a doseresponse type of relationship. The subsequent fractionation carried out to finally isolate the bioactive compounds is shown in Figure 1.

After TLC fractionation step 7, an additional band was obtained and coded as RB21321b. The contents from this band were extracted and subjected to a TLC fractionation step 8, from which four bands were observed (RB21321b1, RB21321b2, RB21321b3 and RB21321b4). The anti-mutagenic activity of all fractions obtained from TLC fractionation procedures 7 and 8 (RB21321a1, RB21321b1, RB21321b2, RB21321b3 and RB21321b4) was evaluated. Anti-mutagenicity results showed that all fractions have inhibitory effects on the mutagenicity of $500 \mathrm{ng}$ of AFB1 in both tester strains, the fraction RB21321a1 (Table 1) inhibited the mutagenicity of AFB1 in > 85 and 61 $\%$ for TA98 and TA100 tester strains, respectively.

Fraction RB21321b1 decreased the reversion rate achieved by $500 \mathrm{ng}$ of AFB1 in a $78 \%$ for TA98 and $62 \%$ for TA100. The Ames test showed that RB21321b2 fraction inhibited the mutagenicity of AFB1 in > $84 \%$ for both strains and a similar behavior was observed in fraction 
RB21321b3, where the inhibition of the inducedmutagenic potential of AFB1 was $83 \%$ for TA98 and $80 \%$ for TA100.

These results suggest that anti-mutagenic compounds were contained in both samples; therefore, RB21321b2 and RB21321b3 fractions were selected for chemical characterization. Finally, fraction RB21321b4 showed a doseresponse type of relationships that failed to be consistent in both tester strains, as those observed for RB21321b2 and RB21321b3.

\section{Structural characteristics}

Fractions with higher antimutagenic potential (RB21321b2 and RB21321b3) were characterized by FT-IR, ${ }^{1} \mathrm{H}$ and ${ }^{13} \mathrm{C}$ NMR spectroscopy, and mass spectrometry. In all cases the spectroscopic data were consistent with the proposed structure. The Fourier Transform Infrared Spectrum (FT-IR) of the fraction RB21321b2 (Figure 2) showed one band at $2959 \mathrm{~cm}^{-1}$ associated to $\mathrm{C}-\mathrm{H}$ stretching of a $\mathrm{CH}^{3}$ group. A sharp and strong band at $1729 \mathrm{~cm}^{-}$ 1 confirmed the presence of the carbonyl group, while the band localized at $1272 \mathrm{~cm}^{-1}$ is associated to the flexion of C-O group present in ester bonds [16]. Fraction RB21321b3 showed a similar FT-IR spectrum than RB21321b2. The C$\mathrm{H}$ stretch vibrations observed at $2958 \mathrm{~cm}^{-1}$ are attributed to methylene groups. Furthermore, the presence of the ester group was evident due to both, the stretching and flexion signals detected at 1729 and $1272 \mathrm{~cm}^{-1}$, respectively, which is associated to $\mathrm{C}-\mathrm{O}$ bonds.

The analysis of the ${ }^{1} \mathrm{H}$ NMR spectrum (400 MHz) (Figure $3 \mathrm{a}$ and $3 \mathrm{~b}$ ) showed two signals at low field: between $\delta=7.51-7.54$ and $\delta=7.69-7.72$ $\mathrm{ppm}$. These signals are evidence of hydrogen characteristically attached to an aromatic ring. A signal at $\delta=4.18-4.32 \mathrm{ppm}$ may be attributed to the protons of an adjacent carbon attached to oxygen present in an ester bond (C-O). Finally, chemical shifts at high field $\delta=0.88-1.71 \mathrm{ppm}$ can be attributed to methyl, methylene, and methine protons. The signals displayed by the ${ }^{1} \mathrm{H}$ NMR spectrum are consistent with the ${ }^{13} \mathrm{C}$ NMR spectrum for both fractions. The ${ }^{13} \mathrm{C}$ NMR spectrum showed a typical signal for carbonyl function group at $\delta=167.7 \mathrm{ppm}$ (Figure 3c and $3 d$ ), which is a characteristic value for carbons in an ester carbonyl group; additionally, the signal observed at $\delta=68 \mathrm{ppm}$ is associated to a carbon from a $\mathrm{C}-\mathrm{O}$ bond. The signals observed between $128 \mathrm{ppm}$ and $132 \mathrm{ppm}$, which are common for aromatic ring carbons; suggest the presence of a compound with an aromatic portion in its structure. Signals between $10 \mathrm{ppm}$ and $38 \mathrm{ppm}$ are characteristics for aliphatic chain carbons.

Table 1: Anti-mutagenic potential of $\mathrm{AFB}_{1}{ }^{\mathrm{a}}$ spiked fractions obtained after thin layer chromatography fractionation step TLC 8 applied to fractions RB21321a $(R f=0.84-0.92)$ and RB21321b $(R f=0.92-1.0)$ (average ${ }^{b}$ TA100 and TA98 revertants/plate, with S9)

\begin{tabular}{|c|c|c|c|c|}
\hline \multirow[t]{2}{*}{ Extract fraction $^{c}$} & \multicolumn{4}{|c|}{ Fraction dilution $^{c}$} \\
\hline & $1 \times 10^{0}$ & $1 \times 10^{-1}$ & $1 \times 10^{-2}$ & $1 \times 10^{-3}$ \\
\hline \multicolumn{5}{|l|}{ TA98 } \\
\hline RB21321a1 & $123 \pm 20^{c}$ & $261 \pm 14^{b}$ & $442 \pm 6^{a}$ & $728 \pm 60^{a}$ \\
\hline RB21321b1 & $182 \pm 19^{b}$ & $301 \pm 86^{b}$ & $470 \pm 19^{a}$ & $572 \pm 14^{\mathrm{bc}}$ \\
\hline RB21321b2 & $97 \pm 16^{c}$ & $297 \pm 58^{b}$ & $491 \pm 80^{a}$ & $548 \pm 28^{c}$ \\
\hline RB21321b3 & $143 \pm 15^{\mathrm{bc}}$ & $340 \pm 22^{a b}$ & $511 \pm 89^{a}$ & $647 \pm 33^{\mathrm{ab}}$ \\
\hline RB21321b4 & $442 \pm 16^{a}$ & $449 \pm 21^{a}$ & $496 \pm 17^{a}$ & $580 \pm 22^{b c}$ \\
\hline \multicolumn{5}{|l|}{ TA100 } \\
\hline RB21321a1 & $512 \pm 99^{a}$ & $654 \pm 17^{\mathrm{a}}$ & $739 \pm 47^{a}$ & $1217 \pm 121^{a}$ \\
\hline RB21321b1 & $498 \pm 10^{a}$ & $536 \pm 22^{b}$ & $762 \pm 123^{a}$ & $840 \pm 29^{b}$ \\
\hline RB21321b2 & $209 \pm 8^{c}$ & $506 \pm 41^{\mathrm{bc}}$ & $740 \pm 25^{a}$ & $849 \pm 21^{b}$ \\
\hline RB21321b3 & $270 \pm 8^{\mathrm{bc}}$ & $461 \pm 3^{c}$ & $505 \pm 73^{b}$ & $661 \pm 88^{b}$ \\
\hline RB21321b4 & $330 \pm 24^{b}$ & $515 \pm 33^{\mathrm{bc}}$ & $614 \pm 18^{\mathrm{ab}}$ & $766 \pm 23^{b}$ \\
\hline
\end{tabular}

${ }^{\mathrm{a}} \mathrm{AFB}_{1}$ (used as positive control) tested at $500 \mathrm{ng} /$ plate induced $838 \pm 52$ and $1326 \pm 54$ revertants/plate for TA98 and TA100, respectively. Spontaneous revertants were $23 \pm 10$ and $146 \pm 17$ for TA98 and TA100, respectively. ${ }^{b}$ Values are means of three replicates \pm standard error mean. Different letters within both, columns and bacterial strain, represent significant differences $(p<0.05)$. ${ }^{\circ}$ Extracts were diluted and spiked with enough toxin to yield $500 \mathrm{ng}$ of pure $\mathrm{AFB}_{1} /$ plate 

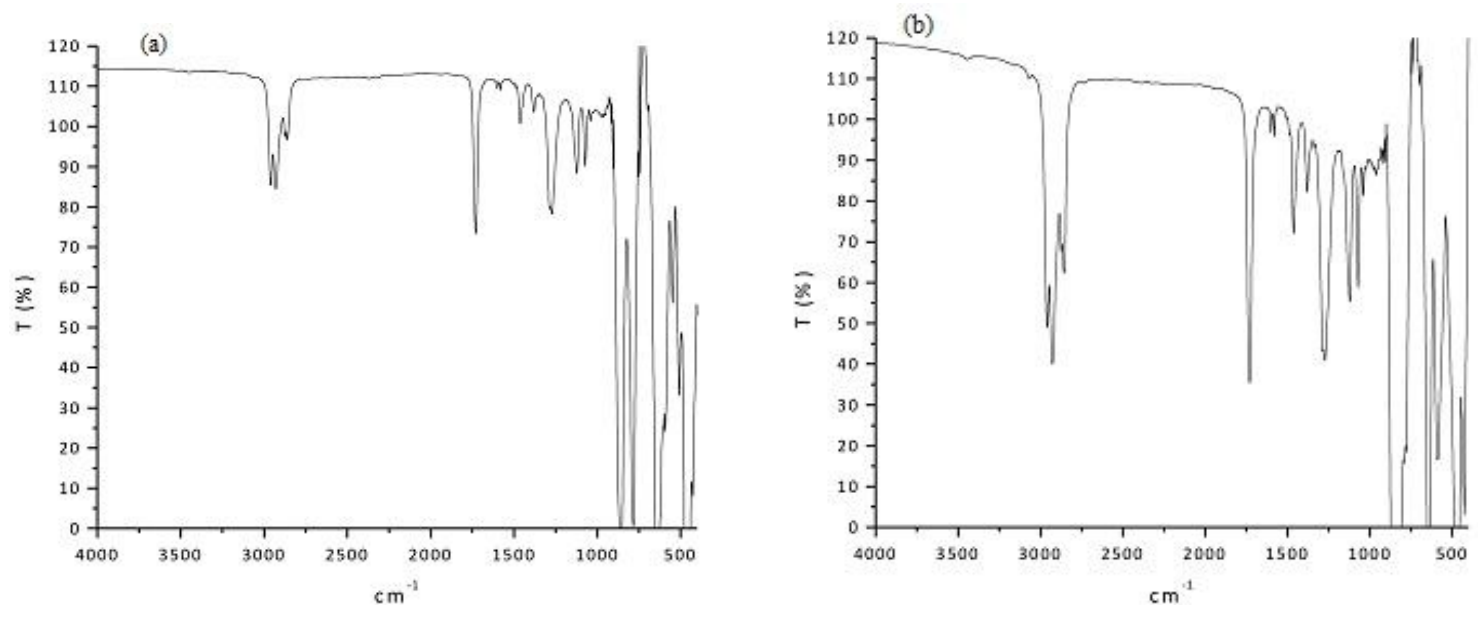

Figure 2: FT-IR spectra of RB21321b2 (a) and RB21321b2 (b) antimutagenic fractions obtained from octopus lipidic extract

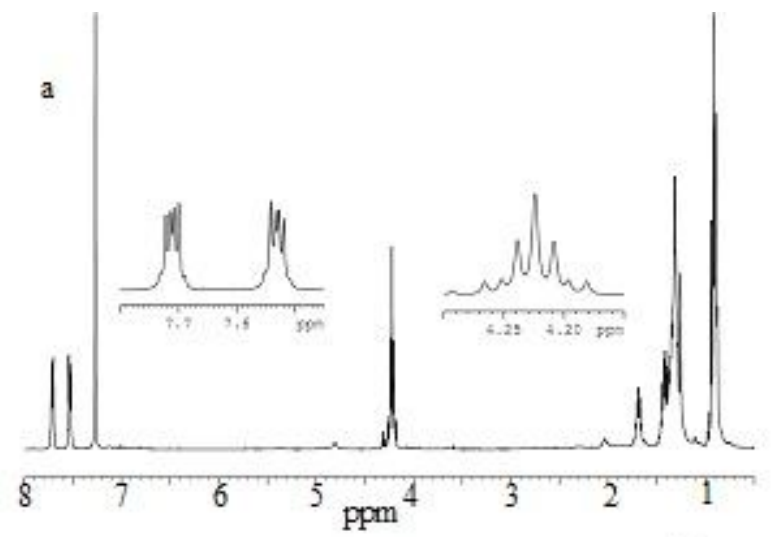

c
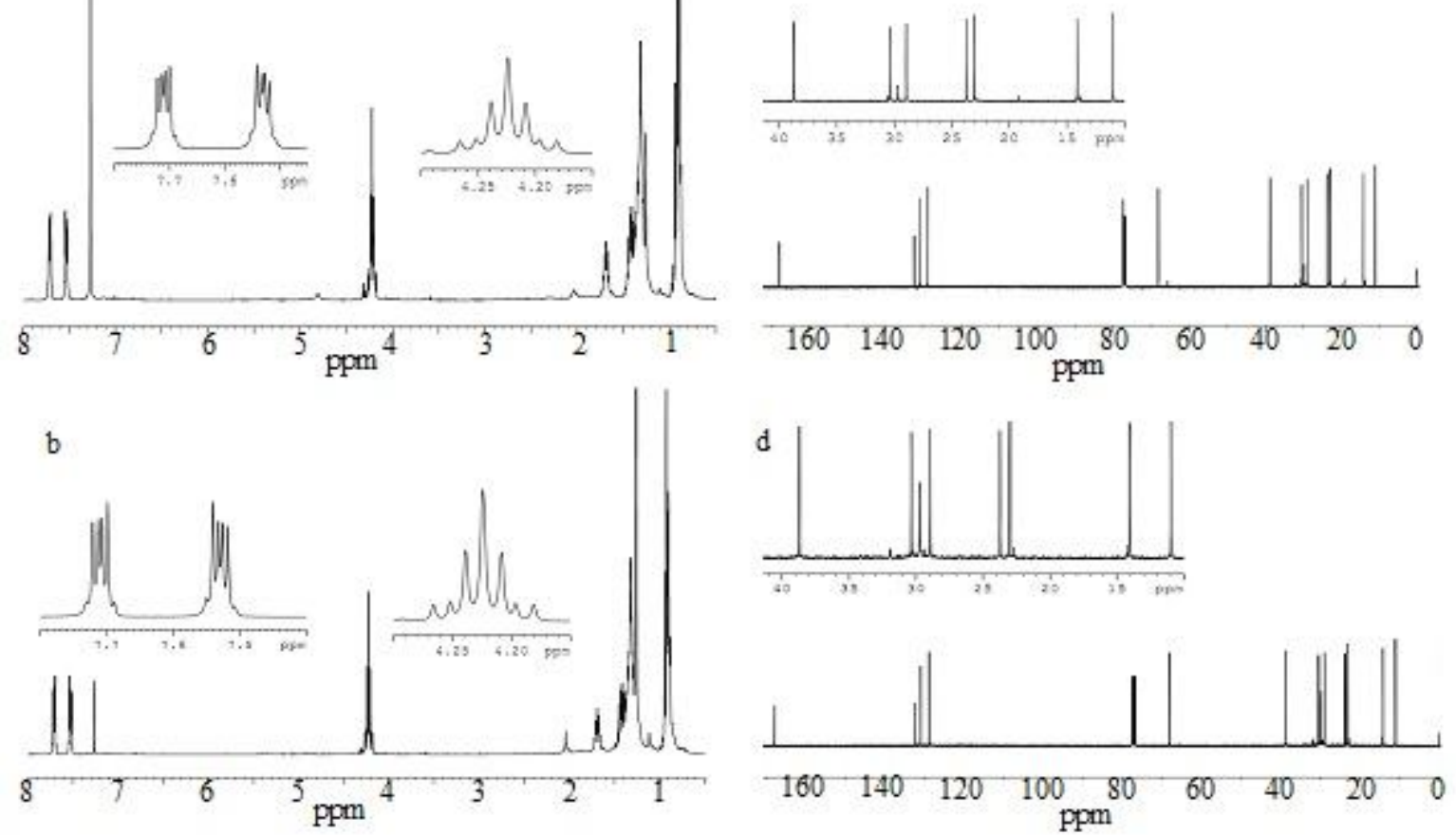

Figure 3: ${ }^{1} \mathrm{H}-\mathrm{NMR}(\mathrm{a}$ and $\mathrm{b})$ and ${ }^{13} \mathrm{C}-\mathrm{NMR}$ (c and d) $\left(\mathrm{CDCl}_{3} / \mathrm{TMS}\right.$ ) spectra of $\mathrm{RB} 21321 \mathrm{~b} 2$ (a and $\mathrm{c}$ ) and RB21321b3 ( $b$ and d) antimutagenic fractions obtained from octopus lipidic extract

Chromatographic analyses of RB21321b2 fraction revealed the presence of two major compounds with retention times of $22.37 \mathrm{~min}$ (peak 1) and with 28.40 min (peak 2), both represent $80 \%$ of the signals (Figure 4a). The mass spectrum of peak 2 showed a $(\mathrm{M}+\mathrm{H})^{+}$peak at $278 \mathrm{~m} / \mathrm{z}$, which suggest the following condensed molecular formula $\mathrm{C}_{16} \mathrm{H}_{22} \mathrm{O}_{4}$. Antimutagenic fraction RB21321b3 represents $>64$ $\%$ of the signals, consisting of only one peak with a retention time of $28.28 \mathrm{~min}$ and $(\mathrm{M}+\mathrm{H})^{+}$peak at
$278 \mathrm{~m} / \mathrm{z}$ (Figure 4b). For both fractions, the mass spectral data suggested a molecule containing an aromatic ring with an aliphatic chain attached through an ester bond. These characteristics coincide with results obtained from ${ }^{1} \mathrm{H}$ RMN and ${ }^{13} \mathrm{C}$ RMN analyses. Based on the above, a chemical structure similar to butyl isobutyl phthalate is proposed for the anti-mutagenic compound present in both fractions. The difference between RB21321b2 and RB21321b3 
might be due to specific structural difference in isomeric nature.

Subsequent fractionation of RB21321 resulted in two bands coded RB21321a and RB21321b, which were subjected to a further fractionation; RB21321a did not separate, while RB21321b fractionated in four different regions (RB21321b1, RB21321b2, RB21321b3, and RB21321b4).

Fractions RB21321b2 and RB21321b3 showed anti-mutagenic potential since they caused the highest inhibition of AFB1 mutagenicity, showing a dose-response type of relationship and lowering the reversion rate to the spontaneous reversion level when these fractions were undiluted. These results suggest the presence of compounds with similar anti-mutagenic characteristics.

Recently, research work has also reported the presence of bioactive compounds from the lipidic fraction of marine organisms. Methanol and chloroform extracts, obtained from Sphyrna lewini, induced evident decrease in the mutagenicity of an indirect acting mutagen [17]. Antimutagenic and antiproliferative studies of lipid extracts from white shrimp suggested chemoprotective properties since reduced the mutagenicity of AFB1 and proliferation of a cancer cell line M12.C3.F6 [18]. According to results obtained from mass spectrometry data base (Figure $4 \mathrm{a}$ and 4b), the isolated antimutagenic compounds were identified as a 1butyl-2-isobutyl-phthalate.

\section{DISCUSSION}

Bioactive phthalate derivatives have been isolated from various natural sources. $\mathrm{Di}(2-$ ethylhexyl) phthalate was isolated as a major bioactive metabolite of a newly isolated soil streptomyces (Streptomyces mirabilis strain NSQu-25). El-Sayed [19] found this compound to have antimicrobial activity against Gram-positive bacteria and yeasts, and also highly cytotoxic for human colon and human breast carcinoma cells. The presence of bioactive phthalate in several natural sources is consistent with our findings.

Lee et al [20] isolated di(2-ethylhexyl) phthalate from Aloe vera Linnen. They found this phthalate derivative to have anti-leukemic and antimutagenic properties as assayed in human tumor cell lines and Salmonella typhimurium TA98 and TA100, respectively.
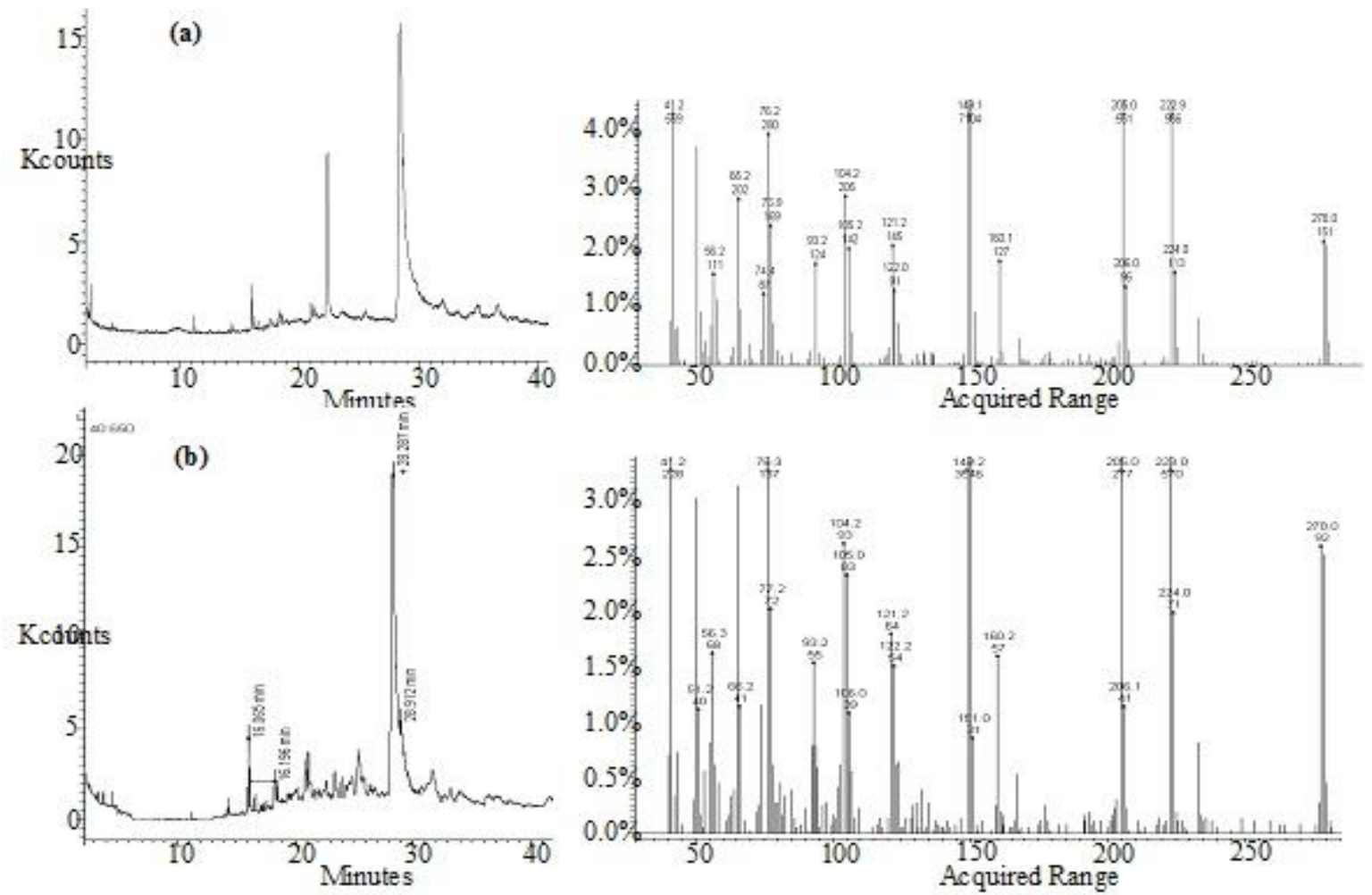

Figure 4: GC-MS spectra of antimutagenic fractions RB21321b2 (a) and RB21321b3 (b) obtained from octopus lipidic fraction 
Inhibition of $\alpha$-glucosidase has been reported for butyl-isobutyl-phthalate, which was isolated from Laminaria japonica rhizoid, considering this phthalate derivative as an important anti-diabetes agent for type II diabetes therapy [21].

However, latest studies have reported the presence of bioactive phthalate derivatives in various marine species, which is consistent with finding from the present research work. Potent antioxidant phthalate derivatives 2-ethyldecyl 2ethylundecyl phthalate, 2, 12-diethyl-11methylhexadecyl 2-ethyl-11methylhexadecylphthalate, and Bis (2ethylheptyl) phthalate have been isolated from Hippocampus kuda [22]. Moreover, bis (2ethylhexyl) phthalate, isolated from marine bacteria Bacillus pumilus MB 40, was found to be an apoptosis inducer in leukemic K562 cells, activating caspases, promoting the releasing of cytochrome $\mathrm{c}$ from mitochondria and decreasing Bcl-2 level [23]. This compound was also capable of arresting cell cycle at sub G0/G1 phase. Also, di-isobutyl phthalate and di-n-butyl phthalate, and bis-[2-ethyl]-hexyl-phthylester have been recently isolated from marine sponges Smenospongia and Niphates, respectively [24].

Authors reported that all three phthalate derivatives exhibited several inhibitory effects on oxidative stress parameters, as well as inhibitory effects on the activity of carbohydrate hydrolyzing enzymes. More recently in our laboratory, we have reported the isolation of an anti-proliferative phthalate derivative from white shrimp (Litopenaeus vannamei), which was identified as di-ethyl-hexyl-phthalate [25]. This compound caused $50 \%$ inhibition of murine M12. C3F6 transformed cell line growth at a concentration of $50 \mu \mathrm{g} / \mathrm{mL}$. Even though phthalates have been reported as marine environmental contaminants [26-28], the existence of various derivative forms of this type of compounds might also suggest biotransformation processes that marine organism may perform on phthalates converting them into bioactive compounds that might be of interest for the biomedical industry.

Based on the above and from results from the present research work, there are evidence supporting that 1-butyl-2-isobutyl-phthalate, isolated from octopus fraction, is the compound responsible for their anti-mutagenic activity; however, further investigation is necessary to fully assess its potential as a biomedical approach. Based on the literature, this is the first report on the identification of an anti-mutagenic compound from octopus.

\section{CONCLUSION}

Fractions RB21321a and RB21321b (CCF7) obtained from octopus (Paraoctopus limaculatus) contain at least 5 lipid fractions. RB21321b2 and RB21321b3 fractions have anti-mutagenic potential with a high percentage of inhibition of AFB1 for Salmonella typhimurium tester strains TA98 and TA100. Based on the findings from this study, the anti-mutagenic compound present in both fractions is a 1-butyl-2-isobutyl-phthalate derivative. However, further studies need to be carried out to determine differences due to possible isomerism. Further work should also focus on the development of new anti-cancer therapeutic agents from these fractions.

\section{ACKNOWLEDGEMENT}

The authors wish to acknowledge CONACyT for financial support via grant project no. 107102 and graduate scholarship granted to CruzRamírez Susana-Gabriela and López-Saiz Carmen-María.

\section{REFERENCES}

1. Braekman J, Daloze D, Chemical defense in sponges. Pure Appl Chem 1986; 58: 357-364.

2. Stankevicins L, Aiub CA, Mazzei JL, Lobo-Hajdu G, Felzenszwalb I. Cytotoxic, mutagenic and antimutagenic screening of Arenosclera brasiliensis acetone and ethanol extracts. Genet. Mol. Res. 2008; 7: $542-548$.

3. Farzaneh-Far R, Lin J, Epel E, Harris W, Blackburn E, Whooley M. Association of marine omega-3 fatty acid levels with telomeric aging in patients with coronary heart disease. Am. Med. Assoc. 2010; 303: 250-257.

4. Shahidi F, Miraliakbari H. Omega-3 (n-3) fatty acids in health and disease: part 1 - cardiovascular disease and cancer. J Med Food 2004; 7: 387-401.

5. Streppel MT, Ocké MC, Boshuizen HC, Kok FJ, Kromhout D. Long-term fish consumption and $n-3$ fatty acid intake in relation to (sudden) coronary heart disease death: the Zutphen study. Eur Heart J 2008; 29: 2024-2030.

6. Spencer $L$, Mann $C$, Metcalfe $M$, Webb M, Pollard C, Spencer $D$, Berry $D$, Steward $W$, Dennison A. The effect of omega-3 FAs on tumour angiogenesis and their therapeutic potential. Eur J Cancer 2009; 45: 2077-2086.

7. Ewaschuk J, Newell M, Field C. Docosahexanoic Acid Improves Chemotherapy Efficacy by Inducing CD95 Translocation to Lipid Rafts in ER2 Breast Cancer Cells. Lipids 2012; 47: 1019-1030.

8. Burgos-Hernández A, López-García R, Njapau H, Park DL. Partial chemical/structural elucidation of anti- 
mutagenic compounds from corn. Toxicology 2001; 166: 161-170.

9. Fedorov S, Makarieva T, Guzii A, Shubina L, Kwak J, Stonik V. Marine two-headed sphingolipid-like compound rhizochalin inhibits EGF-Induced transformation of JB6 P+C/41 cells. Lipids 2009; 44: 777-785.

10. Deniau A, Mosset $P$, Pédrono $F$, Mitre $R$, Le Bot $D$, Legrand A. Multiple beneficial health effects of natural alkylglycerols from shark liver oil. Mar Drugs 2010; 8: 2175-2184

11. Tsai C, Pan B. Identification of sulfoglycolipid bioactivities and characteristic fatty acids of marine macroalgae. $J$ Agric Food Chem 2012; 60: 8404-8410.

12. Gross $H$, Konig $G$. Terpenoids from marine organisms: unique structures and their pharmacological potential. Phytochem Rev 2006; 5: 115-141.

13. Moreno-Félix C, Wilson-Sánchez G, Cruz-Ramírez SG, Velázquez-Contreras $C$, Plascencia-Jatomea $M$, Acosta A, Machi-Lara L, Aldana-Madrid ML, Ezquerra-Brauer JM, Rocha-Alonzo F, et al. Bioactive lipidic extracts from octopus (Paraoctopus limaculatus): antimutagenicity and antiproliferative studies. Evid-Based Compl Alt 2013; 1-12.

14. Burgos-Hernandez A, Peña-Sarmiento M, Moreno-Ochoa F. Mutagencity and antimutagencity studies of lipidic extracts from yellowtail fish (Seriola lalandi), lisa fish (Mugil cephalus) and cazón fish (Mustelus lunulatus). Food Chem Toxicol 2002; 40: 1469-1474.

15. Maron DM, Ames BN. Revised methods for the Salmonella mutagenicity test. Mut Res 1983; 113: 173-215.

16. Pavia DL, Lampman GM, Kriz GS. Introduction to Spectroscopy. USA: Cengage Learning; 2009; pp 680.

17. Samadi S, Emtyazjoo M, Khanipour AA, Moghadasi Z, Nazarhaghighi $F$, Antimutagenic activity of mhloroformic and methanolic extracts of muscle, liver and cartilage of Sphyrna lewini with the Ames test. Iran J Fish Sci 2011; 10: 135-142.

18. Wilson-Sánchez G, Moreno-Félix C, Velázquez C, Plascencia-Jatomea M, Aldana-Madrid ML, EzquerraBrauer JM, Robles-Zepeda R, Burgos-Hernández A. Antimutagenicity and antiproliferative studies of lipidic extracts from white shrimp (Litopenaeus vannamei). Mar Drugs 2010; 8: 2795-2809.
19. El-Syed M. Di-(2-ethylhexyl) phthalate, a major bioactive metabolite with antimicrobial and cytotoxic activity isolated from the culture filtrate of newly isolated soil Streptomyces (Streptomyces mirabilis Strain NSQu25). World App Sci J 2012; 2: 1202-1212.

20. Lee KH, Kim JH, Lim DS, Kim CH. Anti-leukemic and anti-mutagenic effects of di(2-ethylhexyl) phthalate isolated from Aloe vera Linne. J Pharm Pharmacol 2000; 52: 593-598.

21. Bu T, Ming L, Zheng L, Guo $Y$, Lin X. a-Glucosidase inhibition and the in vivo hypoglycemic effect of butylisobutyl-phthalate derived from the Laminaria japonica Rhizoid. Phytother Res 2010; 24: 15881591.

22. Qian ZJ, Kang KH, Kim SK. Isolation and antioxidant activity evaluation of two new phthalate derivatives from seahorse, Hippocampus Kuda bleeler. Biotechnol Bioproc E 2012; 17: 1031-1040.

23. Moushumi A, Jayachandran S. Induction of apoptosis and cell cycle arrest by Bis (2-ethylhexyl) phthalate produced by marine Bacillus pumilus MB 40. ChemBiol Interact 2012; 195: 133-143.

24. Shaaban M, Abd-Alla HI, Hassan AZ, Aly HF, Ghani MA. Chemical characterization, antioxidant and inhibitory effects of some marine sponges against carbohydrate metabolizing enzymes. Org Med Chem Lett 2012; 2: 1-12.

25. López-Saiz, CM, Velázquez C, Hernández J, CincoMoroyoqui FJ, Plascencia-Jatomea M, RoblesSánchez M, Machi-Lara L, Burgos-Hernández A. Isolation and Structural Elucidation of Antiproliferative Compounds of Lipidic Fractions from White Shrimp Muscle (Litopenaeus vannamei). Int J Mol Sci 2014; 15: 23555-23570.

26. Giam CS, Chan HS, Neff GS, Atlas EL. Phthalate ester plasticizers: A new class of marine pollutant. Science 1978; 199:419-421.

27. Hwang HM, Green PG, Higashi RM, Young TM. Tidal salt marsh sediment in California, USA. Part 2: Occurrence and anthropogenic input of trace metals. Chemosphere 2006; 64: 1899-1909.

28. Adeniyi AA, Okedeyi OO, Yusuf KA. Flame ionization gas chromatographic determination of phthalate esters in water, surface sediments and fish species in the Ogun River cachments, Ketu, Lagos, Nigeria. Environ Monit Assess 2011; 172: 561-569. 